\title{
Translating innovative practices into organizational knowledge in the public sector: A case study
}

\section{Stuart Ferguson* and Deborah Blackman**}

\begin{abstract}
Previous research suggests that innovation is heavily informed by strategic management theories and that there is little engagement with practice-based approaches. A case study of a public sector organization identified as doing something innovative is presented. Four main themes emerged. Two themes, the 'importance of a mandate' and the 'development of trust', had their foundations in traditional management practices. The others, 'capacity to challenge the norms' and 'boundary spanning', emerged from practice. It is suggested that a managerial approach that developed a supportive setting for innovation enabled the development of practices whereby innovation was effectively recognized, nurtured and sustained.
\end{abstract}

Keywords: knowledge management, knowledge transfer, innovation diffusion, organizational memory

Received 28 May 2016. Accepted 17 April 2017

\section{INTRODUCTION}

$\mathrm{M}$

uch is written about innovation and its importance for both organizations and nations. This study was prompted, first, by long-running government interest in fostering innovation in the public sector (PS) and the claim that this can be achieved by better management of organizational knowledge (McNabb, 2007; Mulgan, 2007; Swan, 2007); indeed, that better dissemination of organizational knowledge is an intrinsic part of enhancing the 'innovation dynamic' in the PS (ANAO, 2009: 11). Second, it addresses reports that government initiatives to promote knowledge creation in the PS have generally been unsuccessful (Rashman, Withers, \& Hartley, 2009) and the fact that such 'failures' are typically framed as breakdowns in the management of knowledge, with knowledge being represented as something manageable and failure interpreted as the malfunction of managerial processes (Ferguson, Burford \& Kennedy, 2013).

It is often asserted that organizational learning and knowledge are underrepresented in the PS literature, relative to the larger literature that deals with the private sector (Willem \& Buelens, 2007; Rashman, Withers, \& Hartley, 2009; Arora, 2011; Kennedy et al., 2013). Indeed, Hazlett, McAdam, and Beggs refer to 'a paucity of studies that empirically probe the practice of KM in the PS as a situated discourse [rather] than being an extension of private sector development' (2008: 57). Rashman, Withers, and Hartley (2009: 479) see dangers in attempting to 'de-embed' generalizations about

* University of Canberra, Canberra, ACT, Australia

** School of Business, University of New South Wales, Canberra, ACT, Australia

Corresponding author: sfergo@iinet.net.au 
organizational learning and knowledge in private sector organizations and apply them to public organizations as knowledge is not an 'end product' that can be extracted from one context and applied to another. Rashman, Withers, and Hartley suggest that the literature that draws on the private sector underplays aspects of organizational knowledge and learning that are of greater significance to the PS and argue for 'robust theory that takes into account the complex nature of public service organizations' institutional, governance, structural and public value context' (2008).

This pilot study uses a qualitative case study research method to develop a greater understanding of knowledge creation and innovation within the PS. It aims to demonstrate how the knowledge that is produced through the everyday practices of organizational members is, or is not, being captured to support innovation. It is based on a single PS organization and involved interviewing three members of its innovation team and four other key members of staff with direct knowledge of the organization's attempts to foster innovation. The novelty is the analysis of an apparently successful innovation, exploring why it worked when there has been little previous evidence of such innovation achievement within the PS.

\section{INNOVATION IN THE PS}

Factors such as stakeholder expectations and the development of complex interorganizational structures create pressure for PS innovation and learning (Rashman, Withers, \& Hartley, 2009). At the same time, there are contextual issues in the PS that foster conservatism, such as (1) the relative lack of autonomy (LaPalombara, 2001; McNabb, 2007); (2) high levels of public accountability (Rashman, Withers, \& Hartley, 2009; Kothari, Hovanec, Hastie, \& Sibbald, 2011); (3) accountability of PS agencies to a broad range of individuals and organizations (Bontis, 2007; McNabb, 2007); (4) the diffuse and often contradictory nature of public policy and objectives (Bontis, 2007; McNabb, 2007; Willem \& Buelens, 2007); (5) the relative inability of PS agencies to design financial rewards for staff (Chiem, 2001; Bontis, 2007); (6) and the bureaucratic, hierarchical nature of PS organizations (Bontis, 2007; Hazlett, McAdam, \& Beggs, 2008; Marilena \& Elena-Mihaela, 2008).

\section{Strategic management approaches to knowledge creation}

The top-down, strategic approach, characteristic of 'first-generation KM' (Knowledge Management) (Swan, 2007; Grant \& Grant, 2008) is the only one evident in two monographs on KM in the PS (McNabb, 2007; Griffiths, 2009). 'First-generation KM' was heavily influenced by strategic management, with its emphasis on directing work and representing intended activity in plans, strategies and other formulated approaches (Demarest, 1997; Quintas, Lefrere, \& Jones, 1997; Galliers \& Leidner, 2003; Burford et al., 2011), and is the dominant approach taken in most of the case studies reviewed for this project. Examples include (1) the failure of a specific knowledge intervention being framed in terms of poor project management, with the suggestion that strategic intentions should be aligned retrospectively with 'everyday operations' (Chua \& Goh, 2008: 344); (2) a failed management attempt to create an online community by introducing online discussion lists (Hammer, 2007), which demonstrates Gherardi's point that 'a community does not exist before the practice that brings it into being as a community of practice' (2006: 108); and (3) a study of PS procurement that explains the limited success of $\mathrm{KM}$ in terms of 'poor communication of the strategic intent of knowledge transfer within the organization' (Hazlett, McAdam, \& Beggs, 2008: 58).

This emphasis on strategic intent in the PS literature reflects the extent to which established approaches to organizational knowledge have been shaped by strategic management, with a strong focus on the planning and direction of knowledge work. In this traditional, managerialist environment, determination of goals and implementation of action are regarded as separate, with 
planning preceding activity (Mintzberg, 1994; Heracleous, 1998). Although this may be appropriate in some circumstances, it is not suited to an environment that emphasizes knowledge creation, innovation, organizational flexibility and the role of the employee in his/her achievement (Burford et al., 2011).

\section{Practice-based approaches to knowledge creation}

Practice-based theories (Gherardi, 2009; Corradi, Gherardi, \& Verzelloni, 2010; Erden, Schneider, \& von Krogh, 2014) offer an alternative approach, in which learning and knowing are embedded in everyday practices and experience; and in which knowledge emerges from, and contributes to, workplace activity, without direction or control. Whereas planning precedes activity in strategic management theory, practice-based theories presume the integration, even the entanglement, of the two (Burford et al., 2011).

Only three of the PS case studies identified for this project, however, demonstrate any significant engagement with practice-based approaches to management. First, Davenport (2002) reports a KM project that aimed to identify the everyday practices that would allow knowledge work to flourish. Her focus was 'mundane knowledge management', seen in 'the identification and negotiation of aims, tasks, resource allocations, alignments, alliances, and the nature of apprenticeship' (2002: 1038). Second, Swan's study of a British hospital (2007) offers some insights for practice-based approaches, in demonstrating innovation cutting across different established practices. It suggests that specialization can create barriers to those innovation processes that cross boundaries and that investment in practice means that practitioners will attempt to maintain control over their own knowledge domains and work practices, which also acts against innovation (2007). Finally, Fuglsang and Sørensen's study of innovation in a PS elderly care organization (2010) identifies three forms of innovation:

- 'bricolage', described as 'a "do-it-yourself' problem solving activity taking place in daily work situations' (2010: 581);

- management-initiated innovation, which begins as 'relatively abstract ideas, driven by management' in response to external expectations and demands (2010: 586);

- management-mediated innovation, which is problem driven and involves problem definition and solution through 'collective meetings and project groups' (2010: 587).

In this case, the three forms of innovation were only weakly connected, with bricolage largely hidden in daily activities and much innovation happening 'without the knowledge of managers' (Fuglsang \& Sørensen 2010: 593); however, Fuglsang and Sørensen warn that too much management control over bricolage would be undesirable, with work becoming less flexible.

\section{Contribution to the literature}

This review suggests that the PS literature on KM continues to be heavily informed by traditional management theories and to demonstrate little engagement with practice-based approaches and, second, that concerns about the paucity of empirical studies appear to hold true.

This study seeks to address these gaps by conducting a case study in the PS that focusses on the emergence of knowledge and innovation within a PS organization, one that has been identified as doing something innovative. Rather than becoming an account of 'best practice' that characterizes firstgeneration KM (Rashman \& Hartley, 2002; Rashman \& Radnor, 2005), this study will identify the factors that support specific innovations in particular contexts and propose a more practice-based, integrated approach to the management of organizational knowledge for the PS. 


\section{METHODOLOGY}

This pilot study was designed to gather information on the emergence of knowledge and innovation within a specific PS organization that had demonstrated signs of doing something innovative in terms of products and/or practices. The aim was to illuminate local practice, with a view to complementing earlier, theoretical studies (Burford et al., 2011; Ferguson, Burford \& Kennedy, 2013; Kennedy \& Burford, 2013) with empirical data. An interpretative, qualitative research design was adopted because in-depth understandings of phenomena were being sought which were likely to be both contextual and influenced by the individuals involved (Morgan \& Smircich, 1980; Crotty, 1998; Denzin \& Lincoln, 2011). Moreover, the small population meant that individual discussions would offer access to an increased depth of data, enabling the development of greater insights (Merriam, 1995).

A qualitative case study (Eisenhardt, 1989; Yin, 2014) of an innovative team within the organization was developed as analysing a case study is a research strategy which can be focussed on understanding a particular series of events within a given context in order to build, extend or clarify theory (McCaslin and Scott, 2003; Yin, 2014). Critical to the usefulness of the analysis is the clarity of the case boundary (Perren $\&$ Ram, 2004; Yin, 2014). In this research, the case boundary was around a team rather than around a specific innovation. The case study organization had been described to the researchers as a 'change agent', charged with working with industry and changing practice. Discussions with the organization had established the existence of a small team explicitly charged with fostering innovation, which had a history of real success. It was decided to focus on the specific team because, first, an 'innovation team' is a relatively uncommon organizational feature and, second, because it would be central to this study to understand the extent to which such a team contributes to both innovation development itself and to the spread, acceptance and institutionalization of new practices and ideas into corporate knowledge.

It is appropriate to use a single case study in this way as a test or embellishment of a well-established theory (Rowley, 2002; Yin, 2014). In this case, we were looking for evidence that might explain why innovation was successful in this case when it has failed so often elsewhere. The case was developed using in-depth, loosely structured interviews which permitted the interviewer to maintain a structure for later thematic analysis (Hopf, 2004; Qu \& Dumay, 2011) while still allowing a free-flowing conversation which gathered the stories and reflections of each participant.

As the PS literature demonstrated a paucity of good examples and the criteria for success were unclear, an inductive approach was adopted, with interviews focussing on broad questions of participant understanding of innovation; the introduction of new practices or innovations; the capture and sharing of ideas and knowledge in everyday work; knowledge transfer across different groups; and aspects of process that had worked well so far. Interviews were semi-structured in order to permit supplementary prompts, including asking respondents whether other teams in their organization had adopted their practices, how they encourage innovation over time or whether they would do anything differently. The dynamic between the team and other teams within the organization was also considered significant because, while this specific team is explicitly charged with innovation, these other teams are responsible for innovative products, sometimes but not necessarily in collaboration with the 'innovation team'.

The case population was deemed to be seven people at the time of data collection: the three team members (T1, T2 and T3) and four senior managers/directors (O1, O2, O3 and O4) whose roles give them direct knowledge of the organization's attempts to foster innovation and the work of the team at the centre of that endeavour. All were interviewed individually. This phase of the research was exploratory and it was decided not to interview other teams within the organization. Follow-up interviews may be scheduled, depending on the findings of this initial study. To help preserve anonymity, the personal pronoun 'he' has been used to refer to all participants and any individuals mentioned in the interviews. 
Interviews were recorded, transcribed and then coded first, to decipher core meaning, and then to identify, highlight and summarize data related to how innovation emerged, grew or was sustained (Saldana, 2013). From this coding, thematic analysis was used to develop findings. This involved identifying, analysing and reporting patterns within data, with each theme representing some level of patterned meaning within the data (Braun \& Clarke, 2006). Analysis was both top-down, in the sense that themes were anticipated before the interviews and matched to responses, but also emergent when the initial coding was grouped into axial codes from which new themes were developed (Pandit, 1996).

\section{CASE STUDY BACKGROUND}

The case study ('the Organization') is a public service organization responsible for city planning and working with construction industries to produce physical infrastructure across the political jurisdiction. It has $\sim 100$ employees and contractors in its main office (this does not include staff embedded within other directorates or located elsewhere). It has a stated commitment to develop and support innovative and sustainable practices. The Organization is involved in many projects but does not take sole responsibility for a complete project; rather it operates as a 'change agent', with Government seeing its role, as one participant put it, to 'work with industry and change practice', show and 'remove the barriers to innovation' and 'share risk with industry' (O4).

\section{The Team}

The fact that much of the Organization's work practice takes the form of projects means that the Organization relies heavily on teamwork. Teams vary in size from four to seven. Many of them focus on specific geographical areas within the political jurisdiction but others work on particular types of project or, as in the case of the innovation team ('the Team'), work across the Organization.

The Team has five main roles:

- finding new ways of doing things;

- helping other teams within and across the Organization with their business plans (e.g., advising other teams on the sustainability commitments they need to put into their projects);

- servicing the Organization's review panel (discussed below) as its 'secretariat', with one of the Team members preparing panel agendas, minute taking and related administrative tasks;

- conducting environmental reporting - reporting on various indicators at each phase of a project and completing worked examples for each project (with data aggregated for annual reports);

- providing some regulatory feedback or some policy feedback on sustainability matters both internally and externally.

\section{The Panel}

There is a form of 'gateway process' where proposed projects are reviewed by the Organization's review panel ('the Panel'), described as 'a group of experts in their fields' (T1). Although other teams can and do go to the Panel, the Team enjoys a special relationship with the Panel, which adds value to the Team's work. At the time of the interviews, not all proposals were required to go to the Panel but all three Team members mentioned the Organization's stated intention that all the Organization's projects would have to go to the Panel before the business planning stage. 


\section{The Board}

'The Board' is the governing body from which approval is required. The 'gateway process' in which proposals are reviewed by the Panel was described as a significant part of the approval process but, while Panel input can add rigour and support to team projects, teams still need to obtain Board sign-off.

\section{The Consultant}

'The Consultant' is an external project manager who comes in regularly to support the team and 'provide some advice on what's happening' elsewhere and 'where we might position ourselves' (O2).

\section{FINDINGS}

The semi-structured interviews explored predefined areas of work practice such as the introduction of new practices or innovations and the capture and sharing of ideas and knowledge in everyday work. What was important was the discussion of ideas and innovations that had been adopted widely, either making a direct difference to the organizational outcomes or making it possible to do things that would. From the analysis of these conversations it became clear that more than just practice needed to be recognized as part of the case because, of the four main themes that emerged two had foundations in managerial decisions: the importance of a mandate and the development of trust. The other two were more based in practice: capacity to challenge the norms and boundary spanning.

\section{Mandate}

Contrary to the view noted earlier, that the PS is more conservative than the private sector, the participants in this study suggested that industry was the conservative partner, with its 'business-asusual approach', which in part reflected the view that the market tends to be conservative in what it believes a specific product should be. The Organization's role is about demonstrating to its industry partners that there are alternative products; something to which industry partners 'will respond if they see a market response' (O3).

In this context, innovation is seen as 'a leadership exercise', with the Organization providing a demonstration of something new to approval authorities, thus giving industry 'the confidence to follow that direction' (O3). The approach is 'to explore within a current regulation how you can be innovative and be efficient in doing that and satisfy the needs of both the [industry players and consumers] in that process and then use that as a lead to the rest of the industry' $(\mathrm{O} 2)$, with the proviso, however, that industry needs to be part of the innovation and not 'told what to do' (O1).

The Organization also plays a leadership role within the PS, with the Organization demonstrating to similar bodies 'that you can put things together in different ways ... and it can still be cost effective and easy to maintain' (O3).

The mandate from government informs and strengthens the Organization's approach to innovative practice and supports a strong managerial, interventionist approach. One participant mentioned the importance of having a government mandate and a 'statement of intent' to explore things that the private sector could not $(\mathrm{O} 2)$. The Organization can test the regulatory framework, which could be seen as a limitation or even a barrier to innovative practice. In turn, the mandate from the Organization's management shapes the Team's role, which is to look at new ways of doing things and, to some degree at least, invest more time in exploring alternatives than any of the other teams. 
Board approval is particularly important when the project involves doing things in ways that differ from previous practice:

Once the Board's approved something it ... feeds down the line as well, with everybody on board ... it's not just coming from one team as something that may or may not have any status or any rigour behind it (T1).

Participants stressed the criticality of the Panel in terms of achieving management buy-in, particularly if the project team can engage Panel support 'from the beginning' (O4). Panel members can provide a critique of Team proposals on a number of technical levels but the Team can talk to the Panel about process too:

these people have so much background in different processes and things so ... that's had a big impact on how we ... steer the project and also ... gives it a bit of a barometer of what the market or industry acceptance is of the way we do things as well and what's going to become ... too challenging and what's going to work (T1).

The Organization decision that all projects go to the Panel has further 'embedded' the review role: 'So you've got to actually have [Panel] ... involvement from the outset and I think at key points in the project' (O4).

Not only is a panel a requirement; however, 'you also need to have an advocate within the governing board' (O4).

Management buy-in is also a significant factor in ensuring dissemination to other agencies: 'we've had our Director-General write to their Director-General to say this is where we're trying to head with this innovation project' (T1).

Overall, it became clear that mandate was an important structural support which gave the team legitimacy with their colleagues. However, before they could proceed a second factor emerged as needing to be in place.

\section{The development of trust}

It is widely stated that any innovation implementation will need levels of trust between the different parties (see e.g. Nooteboom, 2013). This case was no exception, with it being seen as an important issue, bearing in mind that participants identified a potential for conflict to develop in the Organization because of the divergent parameters under which the different groups work, with the Team afforded more time to explore innovative options than others:

there's incredible pressure on the organization as a whole to deliver product ... and somewhere at the top of the pile, someone sets a number and the organization as a whole gets the impossible task of meeting those numbers, and the numbers are getting bigger and the timeframe's getting shorter ... to then have another group come from sideways and overlay something that maybe slows the whole thing down a bit, you can see that just makes their life harder (O3).

One of the Team members even suggested that, if an innovation had been developed within another group during its everyday practice, it would have been embraced more fully by that group than if it had been developed by the Team, which could be regarded 'like an enemy within' (T2).

The Consultant was a key factor and his appointment emerged as being a part of the managerial plan to develop legitimacy. With his 'background and authority', his attendance at a meeting and support for an idea mean that people believe it and listen: his authority lends credibility to the Team, 'internally as well as externally', while his credibility and 'presence' have value in a Board meeting (T1). The Consultant has 'the confidence of a lot of people here' so other teams trust his ability: 'We might be perceived as being just a sort of bunch of hippies or something like that, but [he's] seen as an industry player' (T2). The Consultant has had a role with the Organization for some years and the Team is 
comfortable running things past him and asking, 'have a look at this, what do you think about it, how does it work?' (T1). In his perceived role as trouble-shooter, the Consultant is regarded as 'good in meetings', because of his high level of industry knowledge, which helps with the kind of tension observed between the Team and one of the other groups (T2).

The issue of trust also emerged as a significant factor in discussions of the special relationship between the Team and the Panel, with the Team acting as the secretariat to the Panel and therefore having 'a very open mind about how [the Panel] can assist on projects and probably more so than most teams within the organization' (T1). According to one participant, the Panel is:

a great sounding board, but also ... you can go into that environment ... and they're there to help ... they're an advisory panel so ... you can feel quite safe. You go in there for a critique but it's actually a good critique and you can have some robust discussion, you don't have to be defensive ... and it's a really great environment to toss around ideas. ... I think that is really important for organizations to have that sort of ability (O4).

One participant suggested that there is not enough use of Panel members as 'mentors': 'the pace of production sometimes doesn't enable intelligent review' (O4). Two Team members suggested that there was sometimes reluctance from other teams to go to the Panel because other teams were under greater pressure to get results quickly although 'a lot of the people now are a lot better with that and they do hold the [Panel] in a lot higher esteem' (T3).

Like the Consultant, the Panel adds to the Team's credibility. Because of the relative lack of experience of Team members, there is a risk that 'they just won't be listened to' $(\mathrm{O} 4)$. Indeed, the same participant saw a 'real problem' in having people in the Team who are not necessarily as experienced as others in the Organization and do not always understand the work practices of the people to whom they are talking; hence, the importance of support from the Panel, which has 'a lot of experience collectively and a very good mix of skills' (O4).

The question of group cohesion emerged in a discussion about the Panel. Two participants mentioned government interest in a broader, cross-agency role for it, however, one saw size as a potential problem. He mentioned that an equivalent panel in another jurisdiction has a much larger panel but that the Organization's Panel 'works really well at the moment; seven or eight people, it's very cohesive, they understand each other, the dialogue is fantastic, constructive. If it gets too big ... it doesn't have the cohesion'. On the other hand, the need for turnover was acknowledged - 'you don't want it to be the same players' (T2).

However, trust was not just seen as emerging because of the structural elements of the Consultant and the Panel; the knowledge-sharing practices themselves also fostered trust over time. One participant referred to different 'panels' within the Organization, with different skill sets, coming together to 'swap scar stories', asking questions such as 'How did you go about it? What did you learn?', typically calling on a member of the Team to outline any issues associated with the establishment of a specific project team, thus drawing on the experience of other teams about how to improve process $(\mathrm{O} 2)$.

For the Team, what led to the development of long-term trust were their ideas being seen to work. In the short term, the mandate enabled them to get things done then, over time, the trust that emerged because they were seen to be successful meant they could undertake more complex and potentially more impactful innovation practices from within a framework that increased their likelihood of success.

\section{Capacity to challenge the norms}

The third theme was developed from narratives which explained how innovation actually happened within the Organization and at this point it became clear that this was about both structure and practice. The structural aspect was that the advent of new perspectives led to the potential for 
new ideas. This was then further enhanced when those involved had the capacity to recognize the boundaries and then challenge them.

Innovation was described as 'something that's not standard practice' (O1); it is 'continuous improvement' (O2); 'it just means trying different things ... and trying to find new ways of doing things that will work better to get a better outcome' (T1); it consists in asking 'how can we do this better, let's try and see if there are other processes, other things that we can be doing to get a better result' (T3). Innovation is not seen 'as simple as spontaneous, creative invention [rather, it is] often about drawing on precedent from, say, different locations and different jurisdictions or different moments in history or whatever, about how they might have solved a similar problem, and looking at ways you can learn from that and then assembling it in a new way and applying it' (O3).

Establishing a team explicitly charged with innovation makes it more likely that recognition of novelty will occur. One of the non-Team participants pointed out that, when you use the word 'innovation' in a group's title, 'that collects a certain type of people with a certain background' (O3). Members of the Team have a 'thirst to explore and research what is innovative', 'a passion for ... what's best practice and what's out there in the industry' and 'the ability to lift their head up from ... what's coming across the desk, the day to day, and look a bit at the horizon about what's coming forward' (O2). One of the Team members echoed the point about being passionate about what they are doing, which drives them in 'chasing something that works quite well but just checking as much out as you can' (T1).

It is also significant that the Consultant comes from outside the jurisdiction and has 'experience with equivalent product outside', with the result that he is 'quite valued' (O2). Another saw it a good thing that the Consultant is 'in and out', with the result that he is 'not part of the furniture' (O4). A similar point was raised in a discussion of the Panel, when it was suggested that there should be a 'mix', with people who 'understand ... all of these rules and the planning context, the political context' and those who 'come with fresh eyes or [from] where things are done a bit differently' (T2).

In seeing innovation as 'something that is not standard practice', one participant explained it is difficult to achieve 'within the rules', which means that its replication requires 'concessions to break the rules' $(\mathrm{O} 1)$ and it was such rule breaking that was identified as the important practice in terms of knowing the rules then being able to know and capitalize upon where there might be flexibility, what to challenge and 'what is just not worth challenging' (T2). Participants saw the constraints presented by the many rules and regulations surrounding the Organization's core business as potential barriers to innovation. As one put it, 'I can understand why there are rules because it means everybody uses ... rules of thumb ... and that's important., but you've got to be able to challenge and innovate' (O4). Another commented that regulations can block innovative practices, in which case it may be 'worth exploring how you might change that regulation to achieve what it's intending to do but maybe in a more refined way' (O2).

Another non-Team member saw a problem in the Team not always understanding the work practices of the people to whom they are talking $(\mathrm{O} 4)$ but one of the Team saw merit in their own recognition 'that we're not the experts at this and that we're learning so much along the way ourselves' (T1). The relative lack of background or expertise means that the Team spends more time in research:

probably what helps with it is that ... none of us have a background ... so we have to ask lots of questions, we have to ... learn all along the way and we don't really know what the restrictions are around what people want you to look at and not look at.... I guess we put a bit of energy into doing that, that other people might just find that they don't have the time to do (T1).

Overall, it was apparent that, in the view of the participants, the key knowledge practice that the Team brought to the Case and that underpinned the achievement of results, was both a willingness and an ability to challenge the accepted ways of working. Once such opportunities were recognized the second key practice came into play: boundary spanning. 


\section{Boundary spanning}

Boundary spanning refers to the process whereby individuals link together different networks with a view to facilitating the transfer of knowledge from one party or system to another, thereby enabling the recognition and understanding of the knowledge of others (Tushman, 1977; Tushman \& Scanlan, 1981; Manev \& Stevenson, 2001; Blackman, Kennedy, \& Ritchie, 2011). It became apparent that this was a core role for the Team, which was manifested in several ways. It was considered a practice as it was something they recognized as necessary, that was dynamic and that needed to be actively undertaken rather than merely a prescribed organizational process.

First, the Team has a role in 'sustainability across the organization in terms of how it educates the rest of [the Organization], how it ... lets other people know what we're doing, how we're going about it' (O2). Thus, one of the Team's core roles was to disseminate the learnings from innovative projects to other teams, informing them 'that these options are available and worthwhile exploring, maybe in a particular context' (O2). Without the Team, some corporate knowledge might be lost:

people come to us a lot to ask us different stuff that they know that we've been looking at and doing as well ... 'Have you looked at this, have you explored that or do know much about it? Do you know who I could talk to about it?' So, it's almost been like a repository of those sorts of sources of information (T1).

There was a sense that the Team acts as a knowledge hub for the Organization: 'people come to us with stuff that they think is useful and ... part of our role is ... to look at it and filter it before we ... let people know or let people know what we think of it' (T1). It was seen as a conduit between other project teams: 'it's imparting knowledge, I suppose, and communicating, and making sure that people are aware of what's out there on the market, what will get through ... standards, and what other projects are doing' (T3). This was achieved through holding networking events and ensuring that information is disseminated internally within the Organization and externally to similar government organizations. Not only did they act as knowledge disseminators because of their own connections and networks (Tushman \& Scanlan, 1981), but they also ensured that things did not have to be relearnt, thereby reducing role overload (Marrone, Tesluk, \& Carson, 2007).

It became clear through the analysis that the Team were acting as 'spanners' (Hawkins \& Rezazade, 2012) in that they were coordinating the understanding and transfer of knowledge between and across teams; for example, one of the Team may meet regularly with another team to support and monitor sustainability developments. In other cases, they were facilitators: 'some of my team didn't quite understand what the project was trying to achieve so they were exhibiting some resistance. So ... both teams explained to each other what we're trying to achieve and I think things were a bit clearer from that' (O1).

In terms of the Team's boundary-spanning role, networking abilities are seen as critical. One of the benefits of good networking is the ability to bring in people with different points of view or with expertise lacking in the Team: 'some of the other people within the organization are really good at introducing us to someone that might be useful to know or might be able to do a bit of work for us' (T1). Two Team members mentioned networking as a key characteristic, singling out a third member of the Team as a great networker: 'so that really helps with talking to lots of different people... I think that's probably one of the characteristics of our team that really helps' (T1). The key networker on the Team had 'been around for quite a while and knows so many people, and [he's] such a socialiser ... [he] does know who the right people are to talk to... outside of the organization as well as in' (T3).

Part of the boundary-spanning role is the movement of knowledge around an organization through the process of 'socialization' (Nonaka \& Takeuchi, 1995), with 'boundary spanners' linking groups in 
an organization by facilitating communication and the sharing of expertise (Pawlowski \& Robey, 2004; cited in Akoumianakis, 2014). The Team accomplishes this to some extent by organizing staff seminars:

We ... make sure we bring in key people from elsewhere in the organization to participate in that discussion. ... there might be something that comes out of it for them ... also they have a wealth of knowledge that we don't have and can ask some questions that we may not know to ask because we don't have the same level of experience (T1).

Speakers are also brought in from outside the Organization, in which case the Team provides speakers with internal context: 'we don't just ...invite someone in to talk about something they're doing elsewhere ... we talk about the focus it has within [the Organization] and how it might be applied' (T1).

Comments from two of the participants (T2, T3) also focussed on documentary sources which can become boundary objects, such as Board papers, Panel minutes, business plans and reports. As well as acting as a repository for other teams, the Team presents papers, which then become another source of organizational knowledge. The Team also provides reports, dividing its projects into different stages, at each of which there are different indicators, and developing a series of worked examples for each of the projects (T2). Information provided by the Team goes into the annual reports for the Organization. The Team writes a lot of briefs and 'ministerials' and,

to make sure that that information is available for the other projects to see what was done in each of the projects and being able to be aggregated as well.... we've got templates for each project to go through and .... we do document as much as we can (T3).

The templates used for computer-aided design and the discipline with which teams structure their written documentation also mean that when someone is pulled into a job, 'they know where to find everything' and 'when the job's archived and you come back to it three years later, you can find that piece of information' (O3). These processes of recording and documentation are very significant in terms of embedding practice in organizational knowledge. Overall it was clear that the Team had an important role in not only supporting the recognition of innovation and relevant knowledge, but also in codifying it as potential boundary objects and enabling shared understandings across team and organizational boundaries.

\section{DISCUSSION}

It is suggested that rarely is a PS innovation an artefact or a clearly observable outcome; it is more likely to be a change in relationships, an amended process, something perceived as new and useful by the stakeholders (Greenhalgh, Robert, Bate, Kyriakadou, MacFarlane, \& Peacock, 2004; Hartley, 2005). The team being analysed supported both innovation of product and innovation of delivery, and studying their practices helped us identify what made the adoption of new ideas possible.

Figure 1 summarizes some of the elements identified as critical for innovation practice, as well as the important inter-relationships. In summary, the mandate from government (1) informs and strengthens the Organization's approach to innovative practice, (2) supports a strong managerial, interventionist approach and (3) is an important structural support, giving the Team legitimacy with colleagues. As another recent study suggests, management prioritization and strategic direction towards innovation play important roles in shaping and supporting decisions to adopt and/or generate innovation (Al-Ansari, Xu, \& Pervan, 2014). Trust is also promoted through managerial intervention, notably through the structural links between the Team and both the Panel and the Consultant, which supports credibility. 


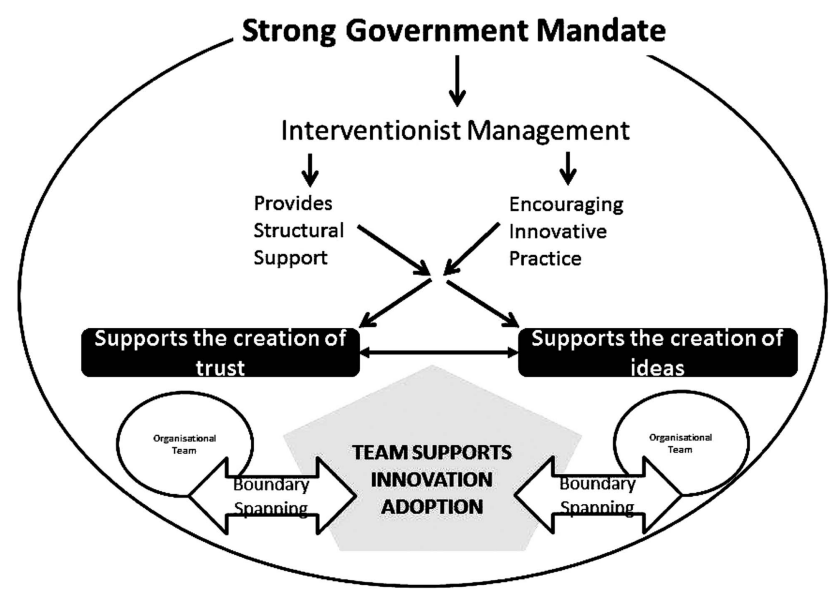

Figure 1. Elements of innovation practice

Capacity to challenge the norms is a practice but it is supported by the Organization's mandate and its stated commitment to innovative practices and sustainable development. The Organization is seen as a 'change agent', working with industry to change practice, having more time to develop projects than industry and, consequently, the Team is afforded freedom to explore different solutions/processes and challenge well-established standards (thus providing a rare instance in which the normally conservative PS is less conservative than the private sector). However, we suggest it is a practice because there is both Team capacity and willingness to actually challenge and change the accepted ways of working. They have tested and experimented with the organizational limitations as a matter of routine.

One of the aims of this study was to demonstrate how the knowledge that is produced through the everyday practices of organizational members is, or is not, being captured to support innovation. It became apparent that this is achieved largely through the Team's second key knowledge practice: boundary spanning. Again, to some extent this was given, for instance, in the Team's role as 'secretariat' to the Panel, but it is also a practice as it is something Team members recognized as being needed, something that is dynamic and requires active routines. It was suggested that the Team has an important role, not only in supporting the recognition of innovation and relevant knowledge, but also in codifying it and enabling shared understandings across team and organizational boundaries. The Team's boundary-spanning role is the key to the translation of innovative practices into organizational knowledge. The case contrasts with the Fuglsang and Sørensen study (2010), in which much innovation happened without the knowledge of the managers. It also suggests a keen consciousness on the part of key players within and outside the Team that innovations cannot simply be transferred from one context to another.

Given the mandate and other elements such as expert support, the Team along with the other teams with which it works develop, not just new and sustainable products, but also new processes. Trust, which did not appear to be particularly strong at the start, developed as the Team successfully challenged norms and developed a track record in its boundary-spanning role - essentially becoming a knowledge hub. Other teams lack the time to document what they have done and come to trust the Team to act in this role. These successes breed further success, with increasing trust, the validation of a knowledge-sharing culture and the increased awareness of the value added by Team and Panel. While the Team's role was given in its mandate, it was also emergent, as other parts of the Organization, especially other teams, became aware of the Team's contribution to ongoing innovation. 


\section{CONCLUSION}

In this paper, we have outlined an example of successful organizational innovation in an endeavour to understand the source of this achievement. Success at this stage of the research was interpreted as the extent to which the case intervention is believed by participants to support innovation through the capture of knowledge produced through the everyday practices of organizational members. Initially, we looked at the literature on innovation in the PS and determined that, while PS innovation is widely espoused, it is rarely achieved. There is a clear gap between what PS innovation will do - the aspirational - and what it does. The successful case reported here is unusual in helping to address this gap and in suggesting what might make PS innovation work better.

It was also clear from the literature review that what has been reported continues to be heavily informed by traditional, often structural management theories and solutions, with little engagement with practicebased approaches. What we have found is, in many ways, unsurprising and yet remains important: it is the combination of the managerial and practice elements which led to success in this case. The managerial approach developed a setting which supported enactment of the practices by which innovation could be recognized, nurtured and effective. This case study charts the interplay of strategic interventions, on the one hand, and largely self-organizing practices on the other. It identifies a degree of alignment between strategic intent and practice that is not apparent elsewhere in the PS literature. Clearly, findings are not generalizable because of the size of the group interviewed, however, the account of innovation practices provided by this small group of key players suggests that there would be significant value in conducting follow-up interviews that include other (project) teams within the organization that interact with the innovation team.

There is also a limitation in terms of the scope and generalizability of this research in the sense that this fruitful interplay between strategic direction and practice cannot be expected to be reproduced in any organization. There may well be less chance of success in the hospital described in the Swan study (2007), which suggested that specialization could create barriers to innovations that cut across established practices. It could be argued that there are greater opportunities for knowledge transfer in an organization such as the case, made up to a significant extent of project teams with strong commonalities in terms of targets and work practices; in other words the context of the innovation strategy is part of this story. Based on the factors that support innovation identified within this case, we suggest that rather than research that judges the efficacy of managerial or practice-based knowledge management approaches, study should progress in the development of a more integrated approach in a range of PS contexts in order to determine if this is a way to overcome the currently lamented lack of successful innovation.

\section{ACKNOWLEDGEMENTS}

University of Canberra, Australia, provided time for the authors to conduct interviews and funding for research assistance.

This manuscript is an original work and is not under consideration or peer review or accepted for publication or in press or published elsewhere. All authors have read and approved the paper.

\section{References}

Akoumianakis, D. (2014). Boundary spanning tactics and 'traceable' connections in cross-organizational virtual alliances. Journal of Enterprise Information Management, 27(2), 197-227.

Al-Ansari, Y., Xu, J., \& Pervan, S. (2014). A study of organisational determinants and innovation practices in Dubai SMEs. International Journal of Innovation Management, 18(1), 1-28. DOI: http://dx.doi.org/10.1142/ S1363919614500030.

ANAO (Australian National Audit Office) (2009). Better practice guide: Innovation in the public sector. Retrieved from http://www.anao.gov.au/bpg-innovation/1_introduction.html. 
Arora, E. (2011). Knowledge management in public sector. Journal of Arts, Science \& Commerce, 2(1), 165-171.

Blackman, D., Kennedy, M., \& Ritchie, B. (2011). Knowledge management: The missing link in DMO crisis management? Current Issues in Tourism, 14(4), 337-354. https://doi.org/10.1080/13683500.2010.489637.

Bontis, N. (2007). Mining the nation's intellectual capital. In S. Borins et al. (Eds.), Digital state at the leading edge (pp. 155-182). Toronto, ON: University of Toronto Press.

Braun, V., \& Clarke, V. (2006). Using thematic analysis in psychology. Qualitative Research in Psychology, 3, 77-101.

Burford, S., Kennedy, M., Ferguson, S. \& Blackman, D. (2011). Discordant theories of strategic management and emergent practice in knowledge-intensive organizations. Journal of Knowledge Management Practice, 12(3). http:// www.tlainc.com/jkmpv12n111.htm.

Chiem, P. X. (2001). Knowledge management in the public sector. CRM Magazine. Retrieved from http://www. destinationcrm.com/Articles/CRM-News/Daily-News/Knowledge-Management-in-the-Public-Sector-45947.aspx.

Chua, A. Y. K., \& Goh, D. H. (2008). Look before you leap: Learning from the experience of a flagging KM initiative at a healthcare organisation in Asia. Aslib Proceedings: New Information Perspectives, 60(4), 335-348.

Corradi, G., Gherardi, S., \& Verzelloni, L. (2010). Through the practice lens: Where is the bandwagon of practicebased studies heading? Management Learning, 41(3), 265-283.

Crotty, M. (1998). The foundations of social research: Meaning and perspectives in the research process. London: Sage.

Davenport, E. (2002). Mundane knowledge management and microlevel organizational learning: An ethological approach. Journal of the American Society for Information Science and Technology, 53(12), 1038-1046.

Demarest, M. (1997). Understanding knowledge management. Long Range Planning, 30(3), 374-384.

Denzin, N. K., \& Lincoln, Y. S. (Eds.) (2011). The SAGE handbook of qualitative research. London: Sage.

Eisenhardt, K. M. (1989). Building theories from case study research. Academy of Management Review, 14(4), 532-550.

Erden, Z., Schneider, A., \& von Krogh, G. (2014). The multifaceted nature of social practices: A review of the perspectives on practice-based theory building about organizations. European Management Journal, 32(5), 712-722.

Ferguson, S., Burford, S. \& Kennedy, M. (2013). Divergent approaches to knowledge and innovation in the public sector. International Journal of Public Administration, 36(3), 169-178. DOI: 10.1080/01900692.2012.749278.

Fuglsang, L., \& Sørensen, F. (2010). The balance between bricolage and innovation: Management dilemmas in sustainable public innovation. The Service Industries Journal, 31(4), 581-595.

Galliers, R. D., \& Leidner, D. E. (2003). Strategic information management: Challenges and strategies in managing information systems (3rd ed.). Oxford: Butterworth-Heinemann.

Gherardi, S. (2006). Organizational knowledge: The texture of workplace learning. Malden, MA: Blackwell Publishing.

Gherardi, S. (2009). Knowing and learning in practice-based studies: An introduction. The Learning Organisation, $16(5), 352-359$.

Grant, K. A., \& Grant, C. (2008). Developing a model of next generation knowledge management. Issues in Informing Science and Information Technology, 5, 572-590.

Greenhalgh, T., Robert, G., Bate, P., Kyriakadou, O., MacFarlane, F., \& Peacock, R. (2004). How to spread good ideas: A systematic review of the literature on diffusion, dissemination and sustainability of innovations in health service delivery and organisation. Report for the National Co-ordinating Centre for NHS Service Delivery and Organisation R\&D (NCCSDO), London. Retrieved from https:/www.cs.kent.ac.uk/people/staff/saf/share/ great-missenden/reference-papers/Overviews/NHS-lit-review.pdf.

Griffiths, P. (2009). Knowledge and information management in the public sector. ARK Group.

Hammer, M. L. (2007). KM at the Virginia Department of Transport. In D. E. McNabb (Ed.), Knowledge management in the public sector: A blueprint for innovation in government (pp. 240-256). Armonk, NY: M.E. Sharpe.

Hartley, J. (2005). Innovation in governance and public services: Past and present. Public Money \& Management, 25(1), 27-34.

Hawkins, M. A., \& Rezazade, M. H. M. (2012). Knowledge boundary spanning process: Synthesizing four spanning mechanisms. Management Decision, 50(10), 1800-1815. https://doi.org/org/10.1108/00251741211279611.

Hazlett, S. A., McAdam, R., \& Beggs, V. (2008). An exploratory study of knowledge flows: A case study of public sector procurement. Total Quality Management \& Business Excellence, 19(1/2), 57-66.

Heracleous, L. (1998). Strategic thinking or strategic planning? Long Range Planning, 31(3), 481-487.

Hopf, C. (2004). Qualitative interviews: An overview. In U. Flick, E. von Kardorff, \& I. Steinke (Eds.), A companion to qualitative research (pp. 203-208). London: Sage. 
Kennedy, M. \& Burford, S. (2013). A comparative analysis of conceptions of knowledge and learning in general and public sector literature 2000-2009. International Journal of Public Administration, 36(3), 155-168. DOI: 10.1080/ 01900692.2012 .749279 .

Kothari, A., Hovanec, N., Hastie, R., \& Sibbald, S. (2011). Lessons from the business sector for successful knowledge management in health care: A systematic review. BMC Health Services Research, 11, 173-183. https://doi.org/org/ 10.1186/1472-6963-11-173.

LaPalombara, J. (2001). Power and politics in organization: Factors against innovation; consensus and public organisations. In M. Dierkes (Ed.), Handbook of organizational learning and knowledge (pp. 557-581). New York, NY: Oxford University Press.

Marilena, C., \& Elena-Mihaela, I. (2008). Knowledge management in the public sector. Annals of the University of Oradea, Economic Science Series, 17(4), 164-168.

Manev, I., \& Stevenson, W. (2001). Balancing ties: Boundary spanning and influence in the organization's extended network of communication. Journal of Business Communication, 38(2), 183-205.

Marrone, J. A., Tesluk, P. E., \& Carson, J. B. (2007). A multilevel investigation of antecedents and consequences of team member boundary-spanning behavior. Academy of Management Journal, 50(6), 1423-1439.

McCaslin, M. L., \& Scott, K. W. (2003). The five-question method for framing a qualitative research study. The Qualitative Report, 8(3), 447-461.

McNabb, D. E. (2007). Knowledge management in the public sector: A blueprint for innovation in government. Armonk, NY: M.E. Sharpe.

Merriam, S. (1995). What can you tell from an $\mathrm{N}$ of 1 ? Issues of validity and reliability in qualitative research. PAACE Journal of Lifelong Learning, 4, 51-60.

Mintzberg, H. (1994). The fall and rise of strategic planning. Harvard Business Review, 107-114.

Morgan, G., \& Smircich, L. (1980). The case for qualitative research. Academy of Management Review, 5(4), 491-500.

Mulgan, G. (2007). Ready or not? Taking innovation in the public sector seriously. London: National Endowment for Science, Technology and the Arts, http://www.nesta.org.uk/library/documents/readyornot.pdf.

Nonaka, I., \& Takeuchi, H. (1995). The knowledge creating company: How Japanese companies create the dynamics of innovation. New York, NY: Oxford University Press.

Nooteboom, B. (2013). Trust, uncertainty, control and innovation. In R. Bachmann, \& A. Zaheer (Eds.), Handbook of advances in trust research (pp. 106-121). Cheltenham, UK: Edward Elgar Publishing.

Pandit, N. R. (1996). The creation of theory: A recent application of the grounded theory method. The Qualitative Report, 2(4), 1-15. Retrieved from http://www.nova.edu/ssss/QR/QR2-4/pandit.html.

Pawlowski, S. D. \& Robey, D. (2004). Bridging user organizations: Knowledge brokering and the work of information professionals. MIS Quarterly, 28(4), 645-672.

Perren, L., \& Ram, M. (2004). Case-study method in small business and entrepreneurial research mapping boundaries and perspectives. International Small Business Journal, 22(1), 83-101.

Qu, S. Q., \& Dumay, J. (2011). The qualitative research interview. Qualitative Research in Accounting \& Management, 8(3), 238-264.

Quintas, P., Lefrere, P., \& Jones, G. (1997). Knowledge management: A strategic agenda. Long Range Planning, 30(3), 385-391.

Rashman, L., \& Hartley, J. (2002). Leading and learning? Knowledge transfer in the Beacon Council Scheme. Public Administration, 80(3), 523-542.

Rashman, L., \& Radnor, Z. (2005). Learning to improve: Approaches to improving local government services. Public Money \& Management, 25(1), 19-26.

Rashman, L., Withers, E., \& Hartley, J. (2008). Long-term evaluation of the Beacon Scheme. Organizational learning, knowledge and capacity: A systematic literature review for policy-makers, managers and academics. London: Department for Communities and Local Government.

Rashman, L., Withers, E., \& Hartley, J. (2009). Organizational learning and knowledge in public service organizations: A systematic review of the literature. International Journal of Management Reviews, 11(4), 463-494.

Rowley, J. (2002). Using case studies in research. Management Research News, 25(1), 16-27.

Saldana, J. (2013). The coding manual for qualitative researchers (2nd ed.). London: Sage. 
Translating innovative practices into organizational knowledge

Swan, J. (2007). Managing knowledge for innovation. In C. R. McInerney, \& R. E. Day (Eds.), Rethinking knowledge management (pp. 147-169). New York, NY: Springer.

Tushman, M. L. (1977). Special boundary roles in the innovation process. Administrative Science Quarterly, 22(4), 587-605. https://doi.org/10.2307/2392402.

Tushman, M. L., \& Scanlan, T. J. (1981). Boundary spanning individuals: Their role in information transfer and their antecedents. Academy of Management Journal, 24(2), 289-305.

Willem, A., \& Buelens, M. (2007). Knowledge sharing in public sector organizations: The effect of organizational characteristics on interdepartmental knowledge sharing. Journal of Public Administration Research and Theory, 17, 581-606.

Yin, R. K. (2014). Case study research: Design and methods. London: Sage. 